\title{
Relationship between Number of Teats and Litter Size in Eutherian Mammals
}

\author{
Deepak Rawal \\ Department of Zoology, Mohanlal Sukhadia University, Udaipur, India \\ Available online at: www.isroset.org \\ Received: 13/Feb/2019, Accepted: 23/Feb/2019, Online: 28/Feb/2019
}

\begin{abstract}
Mammals are vertebrates with hair and mammary glands, which produce milk for nursing their young. Mammals may be divided into two groups Prototheria and Theria. Prototherian are oviparous and Therian are viviparous. Theria is a subclass of mammals. It includes Eutherians (placental mammals) and metatherians (marsupial mammals). Mammals have a wide variety of skin glands, but all seem to be variations of two major glands, Sudoriferous (sweat) and Sebaceous (oil) glands. Mammary glands appear to be modified sebaceous glands. A teat is the projection from the breast or dug or udder or mammary glands of mammals. A litter is the live birth of multiple offspring at one time in animals from the same mother and usually from one set of parents. In this research we test the hypothesis of Gilbert's "one-half rule". According to one half-rule, the average number of young in a litter is one half the typical numbers of teats and the maximum litter size is equal to the total number of teats. To find relationship between number of teats and litter size, various examples of mammalian species are considered and a comparison and correlation was drawn. In this research we also introduced teat formula (Tf) in mammals for the first time.
\end{abstract}

\section{Keywords- Teats, Litter Size, Mammary glands, Eutherian mammals, Teat formula}

\section{INTRODUCTION}

Mammals are vertebrates with hair and mammary glands, which produce milk for nursing their young. Mammals may be divided into two groups Prototheria and Theria. Prototherian are oviparous and Therian are viviparous. Theria is a subclass of mammals. It includes Eutherians (placental mammals) and metatherians (marsupial mammals). Mammals have a wide variety of skin glands, but all seem to be variations of two major glands, Sudoriferous (sweat) and Sebaceous (oil) glands. Mammary glands appear to be modified sebaceous glands. Mammary glands arise in both sexes from a pair of ribbons of ectoderm called milk lines which extend along the ventro lateral body wall of the fetus from the axilla to the groin ${ }^{1}$.

A teat is the projection from the breast or dug or udder or mammary glands of mammals from which milk is ejected for the purpose of nursing young. The number and positioning of mammary glands and teats varies widely among mammals. The protruding teats and accompanying glands can be located anywhere along the two milk lines. In general most mammals develop mammary glands in pairs along these lines. Teats may further divided into true teats (man etc), in which all ducts open at the tip of the nipple as a result of the elevation of the duct bearing area during development and false teats (Ungulates), in which the skin around the duct openings becomes elevated and all ducts empty into cistern. Suckling young are not concerned about the terminology as long as the teats are provident ${ }^{1}$.
A litter is the live birth of multiple offspring at one time in animals from the same mother and usually from one set of parents. The word is most often used for the offspring of mammals, but can be used for any animal that gives birth to multiple young. In comparison, a group of bird's eggs and the offspring that hatch from them are frequently called a clutch, while young birds are often called a brood. Animals from the same litter are referred to as litter-mates. Animals frequently display grouping behavior in herds, swarms, flocks or colonies, and these multiple births derive similar advantages. A litter offers some protection from predation, not particularly to the individual young but to the parent's investment in breeding. With multiple young, predators could eat several and others could still survive to reach maturity, but with only one offspring, its loss could mean a wasted breeding season. The other significant advantage is the chance for the healthiest young animals to be favored from a group. Rather than it being a conscious decision on the part of the parents, the fittest and strongest baby competes most successfully for food and space, leaving the weakest young, or runts, to die through lack of care. In the wild, only a small percentage of the litter may survive to maturity, whereas for domesticated animals and those in captivity with human care the whole litter almost always survives.

\section{EXPERIMENTAL SECTION}

In this research we test the hypothesis of Gilbert's "one-half rule". According to one half-rule, the average 
number of young in a litter is one half the typical numbers of teats and the maximum litter size is equal to the total number of teats. To find relationship between number of teats and litter size, various examples of mammalian species are considered and a comparison and correlation was drawn. In this research we also introduced teat formula (Tf) in mammals for the first time. Teat formula is a formula expressing the number and kinds of teats possessed by a mammal in milk line. Teat formula must consider as mammalian species character like dental formula. A teat formula (Tf) should write in the form of five initials like $\mathrm{nAx}, \mathrm{nT}, \mathrm{nAb}, \mathrm{nI}=$ Total teats. Where Ax denotes Axillary teat, $\mathrm{T}$ denotes Thoracic teat, $\mathrm{Ab}$ denotes abdominal teat and I denotes inguinal teat. Further $\mathrm{n}$ is number of teat. For example Tf of man would be $0,2 \mathrm{~T}, 0,0=2$ teats.

Teat formula is as follows:

Teat formula $(T f)=\mathrm{nAx}+\mathrm{nT}+\mathrm{nAb}+\mathrm{nI}$

Where, $\mathrm{n}=$ number of teats

Ax $=$ Axillary teats

$\mathrm{T}=$ Thoracic teats

$\mathrm{Ab}=$ Abdominal teats

I = Inguinal teats

For example Teat formula for man is as follows:

$T f_{\text {Homo sapiens }}=\mathrm{nAx}+\mathrm{nT}+\mathrm{nAb}+\mathrm{nI}$

$T f_{\text {Homo sapiens }}=0 \mathrm{Ax}+2 \mathrm{~T}+0 \mathrm{Ab}+0 \mathrm{I}$

$T f_{\text {Homo sapiens }}=2 \mathrm{~T}$

It means Homo sapiens have 2 thoracic teats.

For mammalian species we must also consider Teat formula as their distinguished character like we consider dental formula in them because it is main and provident character of mammals.

\section{RESULTS AND DISCUSSION}

Variations in litter sizes and number of teats are special features of mammalian diversity. Pearl $(1913)^{2}$ reported that there are two traits are correlated. He found a significant positive relationship between number of mammae and litter sizes for 90 wild and domestic mammals, representing all orders. This relationship was described by the equation $\mathrm{L}=0.56 \mathrm{M}+0.53$, where $\mathrm{L}=\mathrm{Litter}$ size and $\mathrm{M}=$ number of mammae. Gilbert $(1986)^{3}$ rediscovered the significant positive relationship between mean number of mammae and mean litter sizes among 266 species of rodents, mainly in the families: Muridae, Cricetidae and Sciuridae. This relationship was described as $\mathrm{L}=0.46 \mathrm{M}+0.39$. Except during lactation, the teats of the Opossum are hygienically stored in depressions within the skins. Patches of undifferentiated mammary tissue develop along the milk lines, invade the dermis and then spread under it in the superficial fascia. As development progress, a nipple forms above each patch. Further development of mammary tissue usually occurs in a circular patch beneath each nipple. As the female mammal approaches sexual maturity, rising titers of female sex hormones cause the juvenile duct system to spread and branch.

Lactation is important factor in the evolution of parental care and reproductive success in mammals. Teat number may have operated as selective pressure on litter size over evolutionary time in wild animals ${ }^{4}$. Some studies on other species have shown a positive correlation between litter size and teat number, but other studies have also disputed this ${ }^{5,6,7}$. Naked mole rats (Heterocephalus glaber) are exceptions to one half-rule. Field caught litters averaged 11.3 young $\pm 6.2(\mathrm{n}=82)$ and captive born litters averaged $11.4 \pm 1.1 \quad(n=43)$ in the field and $11.5 \pm 2.0 \quad(n=29)$ in captivity. Maximum litter sizes were 28 in the field and 27 in captivity, whereas the maximum number of teats was $15^{8}$. Naked mole rats are also examples of having odd number of teats in mammals, which is rare condition in them.

In Prototheria (Monotremes) do not develop typical nipples. Instead in both sexes modified sweat glands produce nutritious secretion, which is lapped off a convenient tuft of hairs by the young. Teats would probably be useless in the Monotremes, since it appears doubtful whether the young hindered by horny beaks and lacking muscular cheeks and lips that could nurse. Through natural selection, there is an optimal litter size for a species, population or individual of a particular age or condition and this optimal number is reflected in the modal or mean litter size. Number of teats effectively limits litter size in a marsupial species if young outnumber functional teats at birth such that supernumerary ones die soon after. This condition is typical of polyprotodont marsupials for example in Virginia opossum (Didelphis virginiana), which generally have 13 teats ${ }^{9}$ and in Tasmanian devil (Sarcophilus harrisii), have four teats and a modal litter size of four ${ }^{10,11}$. In contrast medium to large sized species of marsupials, such as Kangaroos, Wallabies and larger Possums typically have four teats but a single young per litter. In those species number of eggs shed at ovulation controls litter size. Mammalian neonates can be divided into two categories, one is altricial (those born essentially naked, with eyes and ears closed, with poorly developed nervous and thermoregulatory systems) and Precocial (born well furred, with eyes and ears open and well developed nervous and thermoregulatory systems). In mammals with an obligate teat attachment phase of development, such as marsupials, litter size obviously cannot exceed the number of mammae ${ }^{12}$.

During pregnancy a battery of hormones causes the formation of sac like secreting terminal (alveoli) at the ends of the duct system. The distribution and number of mammary glands and nipples vary with the species. Nipples may be axillary, thoracic, abdominal and inguinal. A single pair of thoracic nipples occurs in apes and man. Bats also 
have thoracic nipples. Insectivores and some lemurs have one pair of thoracic and one pair of inguinal nipples. Flying Lemurs and Marmosets have a single pair in the armpit (axillary nipples). In Cetacea, nipples occur near the groin (inguinal nipples). In Pigs, Dogs, Edentates and many other mammals, a series of axillary, thoracic, abdominal and inguinal nipples is scattered all along the milk line. Supernumerary nipples may occur in any mammal including man. In general there are sufficient nipples for the number of young in a litter and they are in locations appropriate to the habits of the species.

Kratochwil (1971) ${ }^{13}$ and Kratochwil and Schwartz $(1976)^{14}$ reported that the development of mammary tissue in mice is influenced by androgens. The presence of androgens inhibits mammary tissue development. Specialized adaptations of gestation and lactation characteristic are limited to female mammals. It means females are highly adapted for parental investment, whereas males are physically associated with offspring during early development ${ }^{15}$. Number of young produced per litter is often not the maximum number that a female can reproduce in a breeding event but represents a complex set of tradeoffs between the mother's costs of reproduction and her future reproductive potential and between number and size of young $^{16}$.

Human females have prominent breasts even when they are not lactating, due to fat deposits around the actual mammary glands. Some scientists proposed that they evolved for the purpose of sexual attraction. Some scientists believe that breasts are actually an honest signal of reproductive potential. Some think breasts mimic honest signals. A theory also suggests that breasts evolved in response to the shape of the baby's face. Polythelia, the condition of having extra nipples and Polymastia, the condition of having extra breast are harmless and redundant in humans. Accessory nipples, if presents look much like moles or brown dots in humans.

If we see its evolutionary perspective, we can say that both traits (number of teats and litter size) show coevolution. It is clear that teat feeding is extreme case of maternal care and emotional attachment. Emotional attachment requires highly developed conscience and nervous system with well developed sensory organs which are present in mammals. Here the evolutionary dilemma arise that number of teats drives litter size or litter size drives number of teats during evolution. Here both traits drive each other during co-evolution. It means litter size drives number of teats and number of teats also drives litter size. It is an interdependent evolution. Not only teats size and shape but shape and size of lips, mouth and cheek muscles are also shaped during evolution for milk sucking.
It is clear that if litter size exceeds the number of teats, young ones will face hunger. But here we must also consider the physiology of milk production and how much milk is producing from mammary glands of females as it completely depends on its metabolism. If milk is producing at faster rate, then there is no difficulty in exceeding litter size to number of teats because young ones can alternate feeding. It also depends on Precocial or altricial state of young's. Precocial young do not require much milk and they can start eating solid food readily. If number of teats exceeds the litter size there it must be redundant but however if rate of milk production is slow then young ones can feed on more than one teats. Positioning of teats is also important because teats must positioned so that all young can feed properly and simultaneously. Simultaneous feeding is not necessary but young ones generally mimic each other.

\section{CONCLUSIONS}

Oviparous animals produce hundreds and thousands of eggs because of lower rate of survival due to predators and environmental risks. With evolution of viviparity in mammals, they started to release and keep limited number of eggs in their womb to reduce the risk of predators and environmental risks. Litter size and number of teats in Eutherian mammals is limited from 1 to 20 . It is evident from above study that there is strong positive correlation between optimal number of teats and optimal litter sizes due to co-evolution in these traits. It is clear that both traits showing synchrony and divergent evolution in influence of different environments. But it is also true that we cannot generalized "one-half rule" to all mammals because it is affected by many other factors such as their wild or domestic status, their altricial or Precocial state, metabolism, physiology of lactation, weight and age of mother, behavior of sucking, degree of maternal care, hormones, diet, size of new born, size of uterus etc. It means both traits are continuously evolving, dynamic and interdependent.

\section{REFERENCES}

[1] G.C. Kent. "Comparative anatomy of the vertebrates", CV Mosby Company Japan, pp. 465, 1978.

[2] R. Pearl. "On the correlation between the number of mammae of the dam and size of litter in mammals: Interracial correlation", Proceedings of the Society for experimental Biology and Medicine, Vol.10, pp. 27-30, 1913.

[3] A.N. Gilbert. "Mammary number and litter size in Rodentia: the "one-half rule"”, Proc. Natl Acad Sci, USA, Vol.83, pp. 48284830, 1986.

[4] A.E. Eisenberg. "Reproduction in polyprotodont marsupials and similar sized eutherians with a speculation concerning the evolution of litter size in mammals", Yale University Press, New Haven, pp. 291-310, 1988.

[5] K. Kratochwil. "In vitro analysis of the hormonal basis for the sexual dimorphism in the embryonic development of the mouse mammary gland", Journal of Embryology and Experimental morphology, Vol.25, pp. 141-158, 1971. 
[6] K. Kratochwil and P. Schwartz. "Tissue interaction in androgen response of the embryonic mammary rudiment of mouse: Identification of target tissue for testosterone", Proceedings of the National Academy of Sciences, USA, Vol.73, pp. 4041-4044, 1976.

[7] P Stockley and L Hobson. "Parental care and litter size coevolution in mammals”, Proc. R. Soc. B. pp. 283, 2016.

[8] L. Partridge. "Lifetime reproductive success and life history evolution", Academic press London, United Kingdom, pp. 479, 1989.

[9] C.G. Hartman. Possums, University of Texas Press, Austin, pp. 174, 1952.

[10] E.R. Guiler. "Observations on the Tasmanian devil, Sarcophilus harrisii (Marsupialia: Dasyuridae): Reproduction breeding and growth of pouch young", Australian Journal of Zoology, Vol.18, pp. 63-70, 1970.

[11] R.L. Hughes. "Reproduction in the Tasmanian devil, Sarcophilus harrisii (Dasyuridae, Marsupialia)", Royal Zoological Society of New South Wales, Sydney, Australia, pp. 1396, 1982.

[12] J. Tuomi. "Mammalian reproductive strategies: a generalized relation of litter size to body size", Oecologia, Vol.45, pp. 39-44, 1980.

[13] L.E. Jeppensen. "Teat order in groups of piglets reared on an artificial sow. Formation of teat order and influence of milk yield on teat preferences", Appl Anim Behav, Vol.8, pp. 335-345, 1982.

[14] I. Mansergh and D. Scotts. "Aspects of the life history and breeding biology of the mountain pygmy possum, Burromys parvus (Marsupialia- Burramyidae) in alpine Victoria (Australia)”, Aust Mamal Vol.13, pp. 178-192, 1990.

[15] M.M.A. Mahmoud, Z. Szendro and E.B. Nemeth. "Correlation between teat number of does and baby rabbits". All Es Takar, Vol.39, pp. 321-325, 1990.

[16] P.W. Sherman, S. Braude and J.U.M. Jarvis. "Litter size and mammary numbers of naked mole rats: Breaking the one-half rule”, Journal of Mammalogy, Vol.80, I. 3, pp. 720-733, 1999. 